\title{
Laparoscopic adrenalectomy by the lateral transperitoneal approach in patients with a history of previous abdominal surgery
}

\author{
Michał Pędziwiatr, Maciej Matłok, Jan Kulawik, Piotr Major, Piotr Budzyński, Anna Zub-Pokrowiecka, Andrzej Budzyński \\ $2^{\text {nd }}$ Department of Surgery, Medical College, Jagiellonian University, Krakow, Poland
}

Videosurgery Miniinv 2013; 8 (2): 146-151 DOI: $10.5114 /$ wiitm.2011.32942

\begin{abstract}
Introduction: Even the half of patients undergoing laparoscopic adrenalectomy has history of previous abdominal surgeries. However, it is still uncertain if this fact has an impact on the operation itself as well as the postoperative course.

Aim: To analyze the effects of previous abdominal surgery on surgical outcomes in adrenal tumor patients subjected to laparoscopic adrenalectomy.

Material and methods: This study included 268 patients with adrenal gland tumors operated on by means of laparoscopic lateral transperitoneal adrenalectomy: 1) previously subjected to at least one abdominal surgery (group $A$, $n=101$ ), or 2) with no history of previous abdominal operations (group $B, n=167$ ).

Results: Groups A and B did not differ in terms of tumor size $(p=0.132)$, mean operation time $(p=0.456)$, mean intraoperative blood loss $(p=0.754)$, or perioperative complication rate $(p=0.833)$. Dissection of intraperitoneal adhesions was considered difficult in 32 patients from group $A(31.6 \%)$ and 8 subjects from group $B(4.7 \%, p<0.001)$. Conversion was required in three subjects from group $A(2.9 \%)$ and 3 patients from group $B(1.8 \%, p=0.529)$.

Conclusions: Previous abdominal surgery does not constitute a contraindication to laparoscopic transperitoneal adrenalectomy.
\end{abstract}

Key words: adrenal tumors, laparoscopic adrenalectomy, previous surgery.

\section{Introduction}

It was nearly 20 years ago that Michel Gagner removed the adrenal gland laparoscopically for the first time [1]. Since then laparoscopy has developed dynamically, becoming a "gold standard" in adrenal gland surgery [2]. In the hands of an experienced operator, laparoscopic adrenalectomy has many advantages that classical surgery lacks. Established advantages of the laparoscopic approach include shorter operating time, lower blood loss, shorter hos- pitalization, quicker return of the patient to normal activity and a better cosmetic result [3-7].

Interestingly, up to half of patients operated on due to adrenal pathologies have previously undergone other abdominal surgery [8-11]. Presence of post-surgical adhesions that may complicate future surgery, prolong its duration, cause technical difficulties and increase morbidity and conversion rates is a frequent argument against the transperitoneal approach in favor of application of the retroperitoneal approach in these patients. Previous abdominal sur- 
gery is frequently considered a strong indication for use of the retroperitoneal approach by enthusiasts of this technique, although this opinion is not supported by scientific evidence. Nonetheless, the lateral transperitoneal approach is the most frequently used minimally invasive technique for adrenal gland surgery [12-14]. Moreover, in some authors' opinion previous surgery does not influence the outcomes of laparoscopic transperitoneal adrenalectomy [15-17].

Despite ongoing discussion on potential adverse effects of previous abdominal surgery on the course of laparoscopic adrenalectomy by the transperitoneal approach, the relevant literature is relatively scant.

\section{Aim}

Therefore the aim of this study was to analyze the effects of previous abdominal surgery on surgical outcomes in adrenal tumor patients subjected to laparoscopic transperitoneal adrenalectomy.

\section{Material and methods}

This study included 268 patients with adrenal gland tumors operated on in our clinic by means of lateral laparoscopic adrenalectomy between March 2004 and January 2012. Only cases subjected to complete laparoscopic adrenalectomy by the lateral transperitoneal approach were included in further analyses. Exclusion criteria included partial adrenalectomies, resection of the adrenal cysts, and removal of periadrenal tumors.

Two subgroups were distinguished amongst study participants: patients who were previously subjected to at least one abdominal surgery (group $A$, $n=101)$, and subjects with no history of previous abdominal operations (group $B, n=167$ ). Statistical characteristics of patients from group $A$ and $B$ are summarized in Table I.

One hundred and one patients included in group A (37.6\% of the study group) had a history of previous abdominal surgery. Of this number, 52 (51.5\%) patients were subjected to surgery involving the lower part of the abdominal cavity: appendectomy $(n=32,31.7 \%)$ or gynecologic surgery $(n=20,19.8 \%)$. A further 44 (43.6\%) patients had previously undergone laparotomy involving the upper part of the abdominal cavity, including 15 midline laparotomies (14.9\%), 11 laparotomies involving the upper lateral quadrant on the side of adrenalectomy (10.8\%), and 18 laparotomies in the upper quadrant contralateral to the side of adrenalectomy (17.9\%). Finally, five study participants had a history of previous laparoscopic surgery: adrenalectomy of the contralateral gland ( $n=1,0.9 \%)$, cholecystectomy $(n=2,2 \%)$ or ovarian cyst resection $(n=2,2 \%)$. Eighteen patients from group $A$ had previously undergone more than one abdominal surgery.

According to the surgical protocol, in patients with no history of abdominal operations pneumoperitoneum was established with the closed technique using a Veress needle. In patients with a history of previous abdominal surgery resulting in potential risk of adhesions (midline laparotomy or laparotomy ipsilateral to the side of adrenalectomy) pneumoperitoneum was established by an open technique due to safety reasons.

Groups A and B were compared in terms of patient characteristics and surgical outcomes. Moreover, we have compared the perioperative parameters between the subgroups of group A (lower part vs. upper part vs.

Table I. Statistical characteristics of study participants and adrenalectomies they were subjected to

\begin{tabular}{|lccc|}
\hline Variable & Group A $(n=101)$ & Group B $(n=167)$ & Value of $p$ \\
\hline Age, mean \pm SD (range) [years] & $\begin{array}{c}57.04 \pm 11.63 \\
(20-77)\end{array}$ & $\begin{array}{c}51.65 \pm 13.96 \\
(18-81)\end{array}$ & 0.001 \\
\hline Women, $n(\%)$ & $73(72.28)$ & $111(66.47)$ & 0.320 \\
\hline Right adrenalectomy, $n(\%)$ & $46(45.54)$ & $84(50.30)$ & 0.480 \\
\hline Tumor size, mean \pm SD (range) $[\mathrm{cm}]$ & $3.81 \pm 1.64$ & $4.18 \pm 2.13$ & 0.132 \\
& $(1.4-12)$ & $(1-16)$ & 0.456 \\
\hline Operation time, mean \pm SD (range) $[\mathrm{min}]$ & $79.87 \pm 31.72$ & $83.30 \pm 35.86$ & $(30-160)$ \\
& $(30-180)$ & $63.47 \pm 160.93$ & $(0-500)$ \\
\hline Loss of blood, mean \pm SD (range) $[\mathrm{ml}]$ & $69.34 \pm 140.61$ & $(0-1500)$ & 0.754 \\
\end{tabular}


laparoscopic surgery, and one vs. more than one previous abdominal surgery). The difficulties on dissection were always assessed by the same person (A.B.), participating in the surgery as a principal operating or assisting surgeon.

All the procedures were approved by the Local Ethics Committee of the Jagiellonian University in Krakow, and the subjects gave their written informed consent before the start of any procedure.

\section{Statistical analysis}

Continuous variables were presented as arithmetic means and their standard deviations (SD). Their normal distribution was tested with the Kolmogorov-
Smirnov test. Arithmetic means between the A and B groups were compared using the Student $t$ test or Mann-Whitney $U$ test, and between subgroups of group A with ANOVA or Kruskal-Wallis ANOVA. Distributions of categorical variables were compared with a $\chi^{2}$ test or Fisher's exact test. Calculations were performed using Statistica 7 (StatSoft ${ }^{\circledR}$, Poland) software, with statistical significance defined as $p \leq 0.05$.

\section{Results}

Groups A and B did not differ in terms of tumor size evaluated by means of preoperative CT (Table I). Histopathological characteristics of removed adrenal tumors are summarized in Table II. Dissection of intra-

Table II. Histological types of the adrenal gland tumors removed from the study participants

\begin{tabular}{|c|c|c|c|}
\hline Histological type & Group A $(n=101)$ & Group B $(n=167)$ & Value od $p$ \\
\hline Pheochromocytoma & $26(25.74 \%)$ & $50(29.94 \%)$ & 0.460 \\
\hline Hormonally active tumor: & $32(31.68 \%)$ & $46(27.54 \%)$ & 0.470 \\
\hline Virilizing tumor & 2 & 2 & 0.609 \\
\hline Cushing syndrome & 16 & 27 & 0.944 \\
\hline Conn's syndrome & 14 & 17 & 0.361 \\
\hline Hormonally inactive tumor: & $43(42.57 \%)$ & $71(42.51 \%)$ & 0.992 \\
\hline Benign & 33 & 58 & 0.730 \\
\hline Malignant & 10 & 13 & 0.549 \\
\hline
\end{tabular}

Table III. Cases of conversion in the study participants

\begin{tabular}{|cllll|}
\hline Reason & Age/gender & Histologic type & Size/site & Previous surgery \\
\hline Group A & & & & \\
\hline Neoplastic infiltration & 63 years/F & Pheochromocytoma & $5 \mathrm{~cm} /$ left & Classical cholecystectomy \\
\hline Neoplastic infiltration & 51 years/M & Squamous cell lung cancer & $8 \mathrm{~cm} /$ right & Classical appendectomy \\
\hline Dense adhesions & 76 years/F & Incidentaloma & $\begin{array}{l}4.4 \mathrm{~cm} / \\
\text { right }\end{array}$ & $\begin{array}{l}\text { Classical cholecystectomy, } \\
\text { appendectomy, } 2 \text { laparotomies } \\
\text { due to jejunal obstruction }\end{array}$ \\
\hline Group B & & & & \\
\hline Cardiac dysrhythmia & 74 years/M & Pheochromocytoma & $6.7 \mathrm{~cm} /$ left & \\
\hline Injury of the tumor capsule & 31 years/F & Adrenocortical cancer & $16 \mathrm{~cm} /$ right & \\
\hline Injury of the splenic colic flexure & 56 years/F & Cushing syndrome & $4.6 \mathrm{~cm} /$ right & \\
\hline
\end{tabular}


Table IV. Intra- and postoperative complication rates in the study participants

\begin{tabular}{|c|c|c|c|}
\hline Complication & Group A $(n=101)$ & Group B $(n=167)$ & Value of $p$ \\
\hline Intraoperative complications: & $1(0.99 \%)$ & $3(1.80 \%)$ & 0.598 \\
\hline Injury of diaphragm/pneumothorax & - & 1 & 0.436 \\
\hline Injury of inferior vena cava & - & 1 & 0.436 \\
\hline Injury of left colic flexure & - & 1 & 0.436 \\
\hline Cardiac dysrhythmia & 1 & - & 0.198 \\
\hline Postoperative complications: & $3(2.97 \%)$ & $5(2.99 \%)$ & 0.991 \\
\hline Bleeding requiring re-operation & 1 & 2 & 0.876 \\
\hline Hematoma with no intervention required & 1 & 2 & 0.876 \\
\hline Circulatory insufficiency & 1 & - & 0.198 \\
\hline Respiratory insufficiency & - & 1 & 0.436 \\
\hline Wound suppuration & $2(1.98 \%)$ & $3(1.80 \%)$ & 0.914 \\
\hline Total & $6(5.94 \%)$ & $11(6.59 \%)$ & 0.833 \\
\hline
\end{tabular}

peritoneal adhesions was considered difficult if it required more than 5 min of the operating time. This condition was present in nearly one third of patients from group $A(n=32,31.6 \%)$ and only eight subjects from group $B(4.7 \%, p<0.001)$. No significant differences were observed between the groups in mean operation time or mean intraoperative blood loss (Table I).

Conversion was required in 6 (2.2\%) study participants, including 3 subjects from group A (2.9\%) and 3 patients from group $B(1.8 \%, p=0.529)$. Tumor size and suspicion of its malignant character were the most frequent reasons for conversion $(n=3)$. Impossibility of safe laparoscopic adhesiolysis resulted in conversion in only 1 female patient who was previously subjected to four laparotomies, including two operations due to adhesion-related intestinal obstruction. Detailed characteristics of study participants who required conversion are presented in Table III.

No mortality was observed in the studied group. Overall, perioperative complications were observed in $17(6.3 \%)$ patients including $6(6.0 \%)$ cases from group $A$ and 11 cases (6.6\%) from group B ( $p=0.833)$. Intraoperative morbidity was observed in 4 cases (1 patient from group A and 3 patients from group B), including injury of the diaphragm with subsequent pneumothorax, injury of the inferior vena cava, injury of the left colic flexure and severe cardiac dysrhyth- mia. None of these conditions required changing of the surgical technique. In two patients, intraoperative morbidity was the reason for conversion to classical surgery (injury of the tumor capsule in a case of suspected adrenal malignancy) or video-assisted surgery (injury of the left colic flexure). Postoperative complications were observed in 8 patients, including 3 cases in group A and 5 cases in group B. Reoperation due to intraperitoneal bleeding was required in 3 cases (1 patient from group A and 2 patients from group B). Additionally, suppuration of the trocar-related wound was observed in 5 patients (2 cases from group A and 3 cases from group B). Detailed characteristics of intra- and postoperative complications are presented in Table IV.

The study groups did not differ significantly in the duration of postoperative hospital stay (group A: mean 1.84 days, range 1-8 days; group B: mean 1.91 days, range 1-6 days). No outpatient procedures were performed in our patients.

Additionally, we compared the perioperative parameters between the subgroups of patients with a history of previous abdominal surgery performed in various regions of the abdominal cavity. The only significant difference was related to the duration of surgery, which was significantly longer in patients who had previously undergone upper abdominal surgery $(87.79 \pm 34.17 \mathrm{~min}$ vs. $71.59 \pm 24.80 \mathrm{~min}$ for lower $\mathrm{ab}$ - 
dominal surgery vs. $91.00 \pm 51.53 \mathrm{~min}$ for laparoscopic surgery; $p=0.047$ ). No significant differences, however, were observed in the morbidity rates or the complexity of dissection assessed by the operating surgeon. Additionally, no significant differences were noted between subgroups of patients divided according to the number of previous abdominal operations.

\section{Discussion}

Seifman et al. observed that the frequency of abdominal operations increases with patient age, and many patients who require adrenal gland resection are over 40 years old [18]. According to the literature, the fraction of patients subjected to adrenalectomy who have a history of at least one abdominal surgery varies from $10 \%$ to $62 \%$ [8-11, 15]. In our study, patients with a history of previous abdominal operations constituted $37.6 \%$ of the cohort.

For 9 years, laparoscopic adrenalectomy by the lateral transperitoneal approach has been the procedure of choice in our center. Noticeably, during this period there were no cases disqualified from laparoscopic adrenalectomy due to previous abdominal surgery. In our opinion, the risk of inadvertent injury of abdominal organs during an early stage of the surgery in patients with a history of previous operations may be reduced if pneumoperitoneum is established by an open technique rather than using the Veress needle. We prefer the transperitoneal approach due to the larger operating field enabling removal of larger tumors, clearer insight into the operating field anatomical landmarks, and better evaluation of the extent of the disease in case of malignancy.

Appendectomy, cholecystectomy and hysterectomy in female patients are among the most frequent types of abdominal surgery performed these days. In our study group adrenalectomy was most often preceded by appendectomy or gynecologic surgery (more than $50 \%$ of cases in total). The high fraction of gynecologic operations is related to the fact that women constituted more than $70 \%$ of group A patients. Other authors also confirm our observation $[15,17,18]$. While no significant differences were observed between groups $A$ and $B$ in terms of gender structure and tumor location, the mean age of patients with a history of previous abdominal surgery was significantly higher compared to non-operated individuals. Similar differences referring to patient age were previously described by Morris et al., Parsons et al., and Seifman et al. [15, 17, 18]. In our study, the compared groups did not differ in terms of histological tumor type and its size. Average time of surgery in group A (77 min) was slightly shorter than in group $B(80.5 \mathrm{~min})$, but this difference was insignificant. Interestingly, around $30 \%$ of subjects from group A required adhesiolysis compared to only $5 \%$ of patients from group B. The previously mentioned lack of significant differences in operating time suggests therefore that the duration of laparoscopic adrenalectomy is not influenced by the incidence of abdominal adhesions.

In this study, the intra- and postoperative morbidity rate was around $6-7 \%$ in total with no significant differences observed between groups A and B. Gumbs and Gagner analyzed surgical outcomes from several centers specializing in laparoscopic adrenal surgery and revealed that the morbidity rate after laparoscopic adrenalectomy by the lateral transperitoneal approach ranged from $5.1 \%$ to $12 \%$, including similar complications as those observed in our study [2]. We compared the conversion rate from our patients to the analogous parameters published by authors who performed at least 100 laparoscopic adrenalectomies by the transperitoneal approach. According to Lezoche et al., the conversion rate after this type of surgery is only $0.9 \%$, compared to $2.7 \%, 3 \%$ and $6 \%$ in studies by O'Boyle et al., Guazzoni et al., Gagner et al. and respectively $[8,9,12,19]$. The highest conversion rate (13\%) was reported by Zeh et al. [20]. In our study, conversion was required in 6 patients (2.2\%) including 3 cases from group A and 3 cases from group B. We noted only one case requiring conversion due to dense adhesions precluding safe dissection. Morris et al. [15] analyzed results from nine American centers where 1,378 laparoscopic adrenalectomies were performed in total. Conversion was necessary in 59 cases (4.2\%), including only 5 cases ( $8.5 \%$ ) due to dense adhesions. In view of the aforementioned data, previous abdominal surgery and resulting adhesions constitute a rather marginal problem in terms of potential conversion necessity.

\section{Conclusions}

Previous abdominal surgery does not constitute a contraindication to laparoscopic transperitoneal adrenalectomy since it does not affect surgical outcomes, operating time, intraoperative blood loss, conversion and morbidity rates or the type of postoperative complications. 


\section{References}

1. Gagner M, Lacroix A, Prinz R, et al. Early experience with laparoscopic approach for adrenalectomy. Surgery 1993; 114: 1120-5.

2. Gumbs AA, Gagner M. Laparoscopic adrenalectomy. Best Pract Res Clin Endocrinol Metab 2006; 20: 483-99.

3. Budzyński A, Pędziwiatr M, Matłok M, et al. Preliminary experience with transperitoneal single incision laparoscopic surgery adrenalectomy. Videosurgery Miniinv 2010; 5: 87-92.

4. Prinz RA. A comparison of laparoscopic and open adrenalectomies. Arch Surg 1995; 130: 489-94.

5. Thompson GB, Grant CS, van Heerden JA, et al. Laparoscopic versus open posterior adrenalectomy: a case-control study of 100 patients. Surgery 1997; 122: 1132-6.

6. Otto M, Dzwonkowski J, Ciąćka T et al. Laparoscopic adrenalectomy in elderly patients. Videosurgery Miniinv 2006; 2: 54-8.

7. Toutounchi S, Makowska A, Krajewska E. Laparoscopic treatment of Cushing's syndrome in a woman in late pregnancy a case presentation. Videosurgery Miniinv 2011; 6: 261-3.

8. Lezoche E, Guerrieri M, Paganini AM, et al. Laparoscopic adrenalectomy by the anterior transperitoneal approach. Results of 108 operations in unselected cases. Surg Endosc 2000; 14: 920-5.

9. O'Boyle CJ, Kapadia CR, Sedman PC, et al. Laparoscopic transperitoneal adrenalectomy. Surg Endosc 2003; 17: 1905-9.

10. Ramacciato G, Paolo M, Pietromaria A, et al. Ten years of laparoscopic adrenalectomy: lesson learned from 104 procedures. Am Surg 2005; 71: 321-5.

11. Chan JE, Meneghetti AT, Meloche RM, et al. Prospective comparison of early and late experience with laparoscopic adrenalectomy. Am J Surg 2006; 191: 682-6.

12. Guazzoni G, Cestari A, Montorsi F, et al. Eight-year experience with transperitoneal laparoscopic adrenal surgery. J Urol 2001; 166: 820-4.

13. Otto M. Laparoscopic surgery for adrenal diseases. Surg Laparosc Endosc Percutan Tech 2004; 14: 355.

14. Otto M, Szostek G, Nazarewski S, et al. Laparoscopic transperitoneal lateral adrenalectomy - method and intraoperative difficulties. Videosurgery Miniinv 2002; 7: 15-20.

15. Morris L, Ituarte P, Zarnegar R, et al. Laparoscopic adrenalectomy after prior abdominal surgery. World I Surg 2008; 32: 897-903.

16. Pohl PP, Meyer A, Lammers BJ, et al. Abdominal preoperation. No contraindication for laparoscopic transabdominal adrenalectomy [German]. Der Chirurg 2008; 79: 571-5.

17. Parsons JK, Jarrett TJ, Chow GK, et al. The effect of previous abdominal surgery on urological laparoscopy. J Urol 2002; 168: 2387-90.

18. Seifman BD, Dunn RL, Wolf JS Jr. Transperitoneal laparoscopy into the previously operated abdomen: effect on operative time, length of stay and complications. J Urol 2003; 169: 36-40.

19. Gagner M, Pomp A, Heniford BT, et al. Laparoscopic adrenalectomy: lessons learned from 100 consecutive procedures. Ann Surg 1997; 226: 238-47.

20. Zeh HJ 3rd, Udelsman R. One hundred laparoscopic adrenalectomies: a single surgeon's experience. Ann Surg Oncol 2003; 10: 1012-7.

Received: 3.06.2012, revised: 9.07.2012, accepted: 24.07.2012. 